\title{
DESCRIÇÃO DA TRADUÇÃO PARA O PORTUGUÊS DE MARCAS DE ORALIDADE NO ROMANCE LES FLEURS BLEUES, DE RAYMOND QUENEAU
}

\begin{abstract}
RESUMO: Este artigo estuda as marcas de oralidade presentes no romance Les Fleurs bleues, de Raymond Queneau, e suas implicações para a tradução. Para tanto, levantam-se as marcas de oralidade caracteristicas da lingua francesa e presentes no romance, bem como as marcas de oralidade do português do Brasil. Em seguida, analisase a tradução As Flores Azuis (inédita), levantando-se as marcas de oralidade nela utilizadas com vistas a causar no leitor brasileiro as impressões provocadas pelo original no leitor francês.
\end{abstract}

Roberto de Abreu

PALAVRAS-CHAVE: Oralidade no romance; tradução literária.

RÉSUMÉ: Cet article étudie les marques d'oralité présentes dans le roman Les Fleurs bleues, de Raymond Queneau, et leurs implications sur la traduction. Pour ce faire, il relève les marques d'oralité caractéristiques de la langue française présentes dans le roman, et relève aussi les marques d'oralité du portugais du Brésil. Ensuite, il analyse la traduction As Flores Azuis (inédite) et relève les marques d'oralité qui y sont utilisées afin de provoquer sur le lecteur brésilien les impressions provoquées par l'original sur le lecteur français.

Mestrando no Programa de Estudos Linguísticos, Literários e Tradutológicos em Francês - FFLCH - Faculdade de Letras - Universidade de São Paulo (USP). 
MOTS-CLÉS: Oralité dans le roman; traduction littéraire.

\section{Introdução}

Raymond Queneau é, dentre os escritores franceses do século $\mathrm{XX}$, talvez aquele que mais tenha se preocupado com a introdução da língua falada na literatura. Tomando consciência do perigo de deixar a língua literária afastar-se da língua falada, Queneau faz da aproximação desses dois extremos seu grande projeto literário, com o objetivo de revitalizar a língua escrita através de um emprego original da língua falada e da utilização de trocadilhos e jogos de palavras.

Ele mesmo deixou claro, em sua produção, a opção por uma língua a qual denomina "neofrancês", definindo-a, principalmente em artigos reunidos no seu livro Bâtons, chiffres et lettres, conforme citado por Espinasse:

Tornou-se evidente para mim que o francês moderno devia finalmente se desligar das convenções da escrita que ainda o envolvem (convenções tanto de estilo quanto de ortografia e de vocabulário) e que ele alçaria voo, borboleta, deixando atrás de si o casulo de seda tecido pelos gramáticos do século XVI e pelos poetas do século XVII. (Queneau apud Espinasse, 1999:35, tradução nossa) ${ }^{2}$

Em 1960, Queneau funda, com François Le Lionnais, o Oulipo (Ouvroir de Littérature Potentielle), um grupo de pesquisa literária e científica. Le Lionnais diz no primeiro manifesto sobre a Literatura Potencial:

Toda obra literária é construída a partir de uma inspiração que deve se acomodar bem ou mal a uma série de regras e de procedimentos que entram uns nos outros como

2 Il me devint évident que le français moderne devait enfin se dégager des conventions de l'écriture qui l'enserrent encore (conventions tant de style que d'orthographe et de vocabulaire) et qu'il s'envolerait, papillon, laissant derrière lui le cocon de soie filé par les grammairiens du XVIe et les poètes du XVII e siècle.

TradTerm, 16, 2010, p. 231-255 
bonecas russas. (...) O que certos escritores introduziram a seu modo, com talento mas alguns ocasionalmente, outros com predileção, outros com insistência mas numa só direção, o Ouvroir de Littérature Potentielle (OuLiPo) pretende fazer sistemática e cientificamente. (Oulipo, 1973:1617 , tradução nossa) ${ }^{3}$

Les Fleurs bleues, publicado em 1965, é o primeiro romance escrito depois da criação do Oulipo e o penúltimo na carreira de Raymond Queneau (antes de Vol d'Icare, de 1968). Dessa forma, encontramos nele todas as características que o autor procurava e aperfeiçoava desde seu primeiro romance, principalmente no que concerne à linguagem.

Para permitir a entrada do francês oral no romance, Queneau empreende uma reforma que se dá em três fundamentos da língua escrita, procurando recriar o léxico, a ortografia e a sintaxe. Procedimentos relativos aos três fundamentos que estão presentes em Les Fleurs bleues. Na verdade, Queneau introduz, na escrita, elementos próprios da língua falada, uma linguagem mais natural e viva, como a que se ouve todos os dias.

Com esse tipo de percepção, neste artigo usaremos o termo oralidade no sentido de representação escrita de elementos característicos da língua falada. Procuraremos, então, estudar as implicações desses procedimentos para a tradução, levantando as marcas de oralidade do francês presentes em Les Fleurs bleues e os tipos de elementos de língua falada do português do Brasil, verificando como são utilizados na tradução.

3 Toute œuvre littéraire se construit à partir d'une inspiration qui est tenue à s'accommoder tant bien que mal d'une série de contraintes et de procédures qui rentrent les unes dans les autres comme des poupées russes. (...) Ce que certains écrivains ont introduit dans leur manière, avec talent mais les uns occasionnellement, d'autres avec prédilection, d'autres avec insistance mais dans une seule direction, l'Ouvroir de Littérature Potentielle (OuLiPo) entend le faire systématiquement et scientifiquement. 


\title{
2. Fundamentação Teórica
}

Como dissemos na introdução, a tradução do romance Les Fleurs bleues, da qual buscaremos analisar aspectos de oralidade, pretende ser uma tradução que estimule no leitor brasileiro aquilo que provoca o original no leitor francês. Trata-se, pois, de uma tradução realizada sob a perspectiva funcional que, segundo Azenha Jr., "examina sobretudo a função que a tradução de um texto de partida deve ter ou tem e considera o texto a partir desse ângulo" (Azenha Jr., 1999:24).

Dentro dessa perspectiva, é a função comunicativa do texto que deve orientar o processo tradutório, uma vez que:

\begin{abstract}
a função comunicativa da tradução - e é bom esclarecer que não se trata aqui da função comunicativa do Texto de Partida, mas sim da função comunicativa do Texto de Chegada, na situação e na cultura de chegada -, é a bússola que deverá nortear toda estratégia de produção da tradução. (Azenha Jr., 1999:37)
\end{abstract}

O próprio Azenha Jr. cita como representantes dessa corrente funcional os trabalhos de Hönig e Kussnaul e a Teoria do Escopo, de Katharina Reiss e Hans J. Vermeer. Reiss, por exemplo, divide o processo de tradução em duas fases: análise e reverbalização. Por sua vez, a análise pode ser dividida em três estágios: definição do tipo de texto, da variedade de texto e a análise do estilo: "na prática, os estágios de análise separados se sobrepõem, particularmente na experiência da tradução" (Reiss, 2004:163, tradução nossa) ${ }^{4}$.

Com tal premissa, a autora define três tipos de texto a partir de sua função comunicativa: texto informativo, cuja função é a comunicação do conteúdo; texto expressivo, cuja função é a comunicação de conteúdo organizado artisticamente; e texto operativo, cuja comunicação é de conteúdo com caráter persuasivo. (idem, ibidem). Assim, de acordo com Reiss, é o tipo de texto que determina o método de tradução:

4 In practice, the separate stages of analysis dovetail, particularly if the translator is experienced.

TRADTERM, 16, 2010, p. 231-255 
a. Se o texto fonte tiver sido escrito para transmitir conteúdos, esses conteúdos devem também se transmitidos no texto alvo. O modo de tradução deve ser de acordo com o sentido e o significado a fim de manter a invariabilidade do conteúdo.

b. Se o texto fonte tiver sido escrito para transmitir conteúdos artísticos, então os conteúdos no texto alvo devem ser transmitidos numa organização artística análoga. O modo de tradução deve ser por identificação. O tradutor identifica-se com a intenção artística e criativa do autor a fim de manter a qualidade artística do texto.

c. Se o texto fonte tiver sido escrito para transmitir conteúdos estruturados persuasivamente a fim de disparar impulsos de comportamento, então o conteúdo transmitido no texto alvo deve ser capaz de provocar impulsos de comportamento análogos no seu leitor. O modo de tradução dever ser adaptativo. Os mecanismos psicológicos do uso de linguagem persuasiva devem ser adaptados às necessidades da nova comunidade linguística. (Reiss, 2004:167)

Ora, um texto literário é escrito para transmitir conteúdos artísticos, enquadrando-se, de acordo com a classificação de Reiss, num texto cuja tradução deverá ser feita por identificação. O texto traduzido deve, pois, manter uma organização análoga à do original, de modo a levar em conta a possibilidade de múltiplos sentidos e de múltiplas interpretações que lhe são inerentes. A tradução deve, portanto, manter na língua de chegada a plurivocidade existente na língua de origem e, na medida do possivel, a polissemia e a intertextualidade. Não cabe ao tradutor resolver ambiguidades que o autor intencionalmente incluiu no original, pois, como diz Michele Bourjea, "completar elipses sintáticas, explicitar ligações apagadas pela parataxe (justaposição de orações) é querer designar arbitrariamente ao leitor um significado único, sacrificando a pluralidade do texto". (Bourjea, 1996:124)

Uma vez definido o tipo do texto que se pretende traduzir, é necessário estabelecer o escopo dessa tradução. Segundo Vermeer, em sua teoria do escopo, a tradução é uma ação e toda ação tem um objetivo, um propósito. Escopo é, justamente, o termo técnico para o objetivo ou propósito de uma tradução. 
Vermeer diz ainda que "toda ação leva a um resultado, a uma nova situação ou evento, e possivelmente a um 'novo' objeto. A ação tradutória leva a um 'texto alvo'; a tradução leva a um translatum, como uma variedade particular de texto alvo" (Vermeer, 2004:221, tradução nossa) ${ }^{5}$.

O tradutor, na sua leitura do original, constrói um sentido, mas, no caso do texto literário, esse sentido não é o único possível; por isso, na criação do texto traduzido, o que o tradutor deve procurar não é transmitir o sentido que construiu, mas manter as características do original, para que o leitor possa construir seu próprio sentido na leitura que faz do texto traduzido.

Segundo Laranjeira, "o bom tradutor é o que produz um bom texto, um bom poema, autônomo, como objeto que, uma vez criado, passa a valer e a viver por si mesmo na relação que gera com seu leitor". (Laranjeira, 2003:38) Nesse sentido, quando nos depararmos com construções na língua de partida que não possam ser reproduzidas na língua de chegada, torna-se necessária uma compensação, pois "não se trata, para o tradutor de 'conseguir dizer' aquilo que o autor 'quis dizer', mas sim de 'fazer' algo semelhante ao que o autor 'quis fazer"'. (Laranjeira, 2003:35)

O escopo de uma tradução literária pode ser, portanto, produzir um texto na língua de chegada que gere no seu leitor e na sua cultura o mesmo impacto do original sobre seu leitor e sua cultura. Para tanto, além da identificação do tipo de texto, que segundo Reiss é essencial para a determinação da estratégia de tradução, é necessária também a identificação do escopo:

Um texto fonte é normalmente composto originalmente para uma situação na cultura fonte; daí seu status de 'texto fonte', e daí o papel do tradutor no processo de comunicação intercultural. (...) Assim, não se espera que a mera transcodificação de um texto fonte, sua mera transposição em outra língua, resulte num translatum efetivo.

5 (...) an action leads to a result, a new situation or event, and possibly to a "new" object. Translational action leads to a "target text" (not necessarily a verbal one); translation leads to a translatum (i.e. the resulting translated text), as a particular variety of target text.

TradTerm, 16, 2010, p. 231-255 
Como diz seu nome, o texto fonte é orientado para a cultura fonte. O texto alvo, o translatum, é orientado para a cultura alvo. (Vermeer, 2004:222, tradução nossa) ${ }^{6}$

A tradução de um texto literário, ainda que em prosa, apresenta características que a aproximam da tradução de poesia: é um texto que possibilita várias leituras, várias interpretações. Isso é tanto mais verdade num romance de Queneau, pois o próprio escritor dizia que a composição de um romance deve obedecer a regras tão estritas quanto as do soneto. Para ele, o romance é, ou pelo menos deve ser, um poema, um poema de forma fixa, com regras estruturais. Em Les Fleurs bleues, como já foi dito, uma dessas "regras" é o uso de características da oralidade da língua francesa.

Nos romances tradicionais há uma tentativa de registrar a oralidade nas falas das personagens, mas é uma oralidade artificial, sempre submetida às regras da lingua culta:

O romance traz diálogos dos quais o mínimo que se pode dizer é que são 'escritos', pronunciá-los em voz alta é quase impossivel; e, ao contrário, a transcrição de um diálogo gravado tem todas as chances de deixar os leitores perplexos, e mais ainda os participantes, a ponto de parecer até incompreensivel. (Pouilloux, 1999:34, tradução nossa) ${ }^{7}$

Queneau procura manter elementos de oralidade tais como são encontrados no francês falado, ainda que isso implique de-

6 A source text is usually composed originally for a situation in the source culture; hence its status as "source text", and hence the role of the translator in the process of inter cultural communication. (...) It is thus not to be expected that merely "trans-coding" a source text, merely "transposing" it into another language, will result in a serviceable translatum. As its name implies, the source text is oriented towards the source culture.

7 Les romans comportent des dialogues dont le moins qu'on puisse dire est qu'ils sont "écrits ", les prononcer à haute voix est presque impossible ; et, à l'inverse, la transcription d'un dialogue enregistré a toutes chances de rendre tout à fait perplexes les lecteurs et plus encore les participants, au point même de paraître incompréhensible. 
formações sintáticas e ortográficas, para dar conta da realização fonética efetivamente encontrada na língua falada. Esses elementos estão presentes não só na fala das personagens, mas também nas palavras do narrador, o que rompe com as regras da narrativa tradicional, e é uma característica do romance francês do século XX. O próprio Queneau cita, em seu romance Bâtons, Chiffres et Lettres, uma carta de Alejo Carpentier, um dos maiores escritores do século XX, em que diz:

A conversação tem um ritmo, um movimento, uma falta de sequência nas ideias, com, em compensação, associações, lembranças curiosas, que não se parecem em nada com os diálogos que preenchem, habitualmente, qualquer romance. (Queneau apud Pouilloux, 1991:34, tradução nossa) $)^{8}$

Escrito com muito mais diálogos do que narração, Les Fleurs bleues é um romance em que Queneau procura criar uma escrita o mais próximo possivel da língua falada. E o próprio autor assim o justifica:

A maioria desses diálogos tem uma sintaxe não habitual na língua escrita e uma leveza mais próxima da conversação real - em que frases quase nunca são terminadas, frequentemente faltam os verbos, e o essencial não é dito, expresso, mas subentendido, sugerido pelo encontro de duas ou três pessoas que falam. Acontece até de os interlocutores seguirem cada um sua fala em duas séries paralelas sem escutarem um ao outro. (Pouilloux, 1991:35, tradução nossa) $)^{9}$

8 La conversation a un rythme, un mouvement, une absence de suite dans les idées, avec, par contre, d'étranges associations, de curieux rappels, qui ne ressemblent en rien aux dialogues qui remplissent, habituellement, n’importe quel roman.

9 La plupart de ces dialogues ont une syntaxe inhabituelle dans la langue écrite et une légèreté si proche de la conversation réelle - où les phrases ne se terminent presque jamais, où les verbes manquent souvent, où l'essentiel n'est pas dit, exprimé, mais sous-entendu, suggéré par la rencontre des deux ou trois personnes qui parlent. Il arrive même que

TradTerm, 16, 2010, p. 231-255 
Para imitar a língua falada, o autor lança mão de mudanças ortográficas, de imitação de sotaques e de gagueira, de sobreposição de turnos conversacionais e de desvios sintáticos. Entendemos "desvios" como construções que não seguem estritamente a norma culta da língua. Como alguns dos desvios utilizados por Queneau são próprios da língua francesa, não podem ser reproduzidos em português por uma tradução literal. Por isso, é necessário o estudo das marcas de oralidade encontradas no português do Brasil, para que se possa, na tradução, compensar com características dessa língua o que não puder ser traduzido diretamente daquela.

Alguns dos elementos encontrados, como repetição, neologismos e mistura de linguas, podem ser reproduzidos numa tradução literal. No entanto, há outros que trazem maiores dificuldades. Os trocadilhos, por exemplo, não são obtidos pela simples tradução literal. Se o importante não é propriamente o significado mas o significante, há que se procurar na língua de chegada outras palavras que possam produzir efeito semelhante. Os provérbios, sendo rimados, também não podem ser traduzidos literalmente.

É necessário, pois, criar em português, quando não é possivel a tradução literal, alguma outra maneira de produzir um efeito no leitor semelhante ao alcançado pelo original sobre um leitor francês. Em português, assim como em francês, há duas linguas diferentes:

Há uma discordância entre língua falada e lingua escrita, uma vez que, em favor da economia, da naturalidade, da simplicidade e da expressividade, a língua oral sacrifica a concordância, a regência, a ordem; quando não, sons, sílabas, palavras e frases. (Urbano, 2000:104)

Como alguns elementos de oralidade são próprios de cada língua, há casos que ocorrem no francês e não no português falado no Brasil. Deve-se, portanto, verificar quais as características desse português e, eventualmente, compensar as manifes-

les interlocuteurs suivent chacun son fil dans deux suites parallèles sans s'écouter. 
tações da oralidade francesa por outras próprias do português do Brasil.

Ao analisar as características do português falado no Brasil, Urbano cita elementos disponíveis nessa língua para que se possam apresentar diálogos com marcas de oralidade em português do Brasil ${ }^{10}$.

\section{Análise de Marcas de Oralidade em Les Fleurs bleues e na tradução}

Levantaremos, a seguir, exemplos de trocadilhos, neologismos, mistura de línguas, provérbios, marcas de língua falada e, finalmente, desvios sintáticos no romance Les Fleurs bleues. Como as referências são todas do romance, será anotado apenas o número da página. Todas as traduções do romance são nossas.

\subsection{Trocadilhos}

A primeira coisa que chama a atenção do leitor, logo no início de Les Fleurs bleues, são os jogos de palavras. Desde o primeiro parágrafo ele já se encontra face a uma série de trocadilhos. Vejamos:

10 Segundo Udinilson Urbano, as principais características da língua falada no Brasil são:

a) fonéticas

- redução de ditongo (mantega por manteiga);

- reduções aferéticas ou sincopadas (tava por estava ou pra por para);

- redução de nd a $n$ e de $m b$ a $m$ (falano por falando ou tamém por também);

- adições e prolongamentos (vocêis por vocês);

- supressão do $r$ final dos infinitivos em ar (precisamos pará). b) sintáticas

- colocação pronominal (Me dá um copo d'água?);

- regência verbal (assistir [a] um filme / tenho a impressão [de] que ele ficou magoado / fui na feira;

- concordância (aqueles monte de pedra / temos que se unir);

- correlação de tempos verbais (se eu pudesse, também era empresário).

TRADTERm, 16, 2010, p. 231-255 
Le vingt-cinq septembre douze cent soixante-quatre, au petit jour, le duc d'Auge se pointa sur le sommet du donjon de son château pour y considérer, un tantinet soit peu, la situation historique. Elle était plutôt floue. Des restes du passé traînaient encore çà et là, en vrac. Sur les bords du ru voisin, campaient deux Huns; non loin d'eux un Gaulois, Eduen peut-être, trempait audacieusement ses pieds dans l'eau courante et fraîche. Sur l'horizon se dessinaient les silhouettes molles de Romains fatigués, de Sarrasins de Corinthe, de Francs anciens, d'Alains seuls. Quelques Normands buvaient du calva. (13)

Encontramos nesse primeiro parágrafo, abrindo o romance, uma série de trocadilhos com os nomes dos povos que o duque observa: o primeiro, um jogo de palavras entre "deux" e "un", pode ser sentido em português pela tradução literal "dois hunos"; o terceiro, uma alusão à moeda francesa também pode ser traduzido literalmente; no quarto, para um jogo fonético com "linceul", houve a necessidade do acréscimo da palavra "além" para lembrar "lençóis"; o segundo, no entanto, que em francês soa como "raisins de Corinthe", significando "uvas passas", não pôde ser mantido em português. Nesse caso, optamos pela expressão "sarracenos de Mans", que soa como "acenos de mão", expressão retomada no capítulo III. O importante nesse caso não era manter a cidade de Corinto, mas encontrar outra que pudesse manter o trocadilho. Eis como ficou a tradução do parágrafo:

Em vinte e cinco de setembro de mil duzentos e sessenta e quatro, de manhãzinha, o duque de Auge postou-se no alto do torreão de seu castelo para considerar, um tantinho que fosse, a situação histórica. Ela estava meio embaçada. Restos do passado se arrastavam ainda cá e acolá, ao léu. Às margens do riozinho vizinho, acampavam dois hunos; não longe deles um gaulês, eduano talvez, molhava os pés audaciosamente na água corrente e fresca. No horizonte desenhavam-se as silhuetas moles de romanos cansados, de sarracenos de Mans, de francos antigos, de alanos, além, sós. Alguns normandos bebiam calvados. 
Outro exemplo de trocadilho encontramos no capítulo III, quando o duque de Auge e seu capelão discutem sobre o significado dos sonhos:

- Bon. Voilà qui me satisfait fort, car jamais n'eus conversation avec un serpent en rêve; ce n'est point comme notre mère Ève.

- Elle ne rêvait point. (44)

Nesse caso, "mère Ėve" faz um trocadilho com a própria palavra "rêve" (sonho). Ora, esse trocadilho (entre Eva e sonho) não pode ser traduzido literalmente para o português. Como não se trata de uma tradução de significado, mas da criação de um texto que seja análogo ao original, optamos, na tradução, por uma compensação com outro trocadilho, "mais sã" por "maçã", fruto que será lembrado no contexto em que se fala de Eva e de serpente:

- Bom. Isso me deixa mui satisfeito, pois nunca conversei com uma serpente em sonho; não é como nossa mãe Eva. - Eva, mais sã, não sonhava.

\subsection{Neologismos}

Assim como com os trocadilhos, encontramos neologismos ao longo de todo o romance. Já no primeiro capítulo, quando o duque de Auge comenta sobre a lentidão da construção da catedral de Notre Dame, encontramos:

- Si on traîne tellement, on finira par bâtir une mahomerie. - Pourquoi pas un bouddhoir ? un confuciussonnal ? un sanct-lao-tsuaire? (15)

Nesse caso, além dos neologismos construídos a partir de Maomé, Buda, Confúcio e Lao Tsé, há ainda trocadilhos com "boudoir", pequeno aposento para senhoras, "confessionnal", confessionário e "sanctuaire", santuário. Na tradução, mantivemos os dois últimos, e o primeiro "boudoir", sem correspondente 
em português, compensamos com uma alusão ao santo sudário, coerente com o contexto em que se fala de religiões:

- Se as obras se arrastam desse jeito, vão acabar constru-
indo uma maomeria.
- Por que não um santo budário? um confucionário? um
santu-lao-tsuário?

No capítulo III, encontramos outros exemplos de neologismos, como os gentílicos em "qu'elle ne s'est pas fait naturaliser roubanche ou zanzébienne." (37), traduzidos por "que não se naturalizou robanche nem zanzebiana.", ou ainda derivado da expressão latina de encerramento da missa ita missa est, em "L'abbé Biroton n'eut pas plutôt itamissaesté que le duc d'Auge l'entraîna(...)" (40), traduzido por "O abade Biroton mal tinha itamissaestado e o duque arrastou-o(...)". Além disso, encontramos uma situação ambígua em que, ironicamente, palavras do francês atual são sonhadas pelo duque em 1264 e apresentadas como neologismos ao abade Biroton. O duque não só confirma que se trata de neologismos e usa o neologismo "neologizar", como explica as regras segundo as quais criou essas palavras:

- Je rêve souvent que je suis sur une péniche, je m'assois sur une chaise longue, je me mets un mouchoir sur la figure et je fais une petite sieste.

- Sieste... mouchoir... péniche... qu'est-ce que c'est que tous ces mots-là? Je ne les entrave point.

- Ce sont des mots que j'ai inventés pour désigner des choses que je vois dans mes rêves.

- Vous pratiqueriez donc le néologisme, messire?

- Ne néologise pas toi-même : c'est là privilège de duc. Aussi de l'espagnol pinaça je tire pinasse puis péniche, du latin sexta hora l'espagnol siesta puis sieste et, à la place de mouchenez que je trouve vulgaire, je dérive du bas-latin mucare un vocable bien françoué selon les règles les plus acceptées et les plus diachroniques. (42)

Nesse caso, na tradução mantivemos "sesta" e "chata", cujo processo de criação pôde ser explicado como em francês, mas 
em vez de "lenço" usamos "espreguiçadeira", pois a etimologia de lenço não poderia ser explicada como o foi em "mouchoir":

- Sonho sempre que estou numa chata, que me sento numa espreguiçadeira, que ponho um lenço na cara e que faço uma pequena sesta.

- Sesta... espreguiçadeira... chata... o que é que são todas essas palavras? Eu não estou sacando.

- São palavras que inventei para designar as coisas que vejo nos meus sonhos.

- Então praticarieis neologismo, senhor?

- Não neologize você: isso é privilégio de duque. Assim, do italiano chiatta eu tiro chiata e depois chata, do latim sexta hora o espanhol siesta depois sesta e, do latim pigritia, pigriça, priguiça e, depois, de preguiça eu derivo um vocábulo de nossa língua tudo de acordo com as regras mais aceitas e mais diacrônicas.

\subsection{Mistura de linguas}

Além de muitas citações de latim, há um episódio em que Cidrolin fala com dois campistas, num diálogo em que se misturam várias línguas europeias e que o próprio Cidrolin chama de neo-babélico:

- Esquiouze euss, dit le campeur mâle, mà wie sind lost.

- Bon début, réplique Cidrolin.

- Capito ? Egarrirtes... lostes.

- Triste sort.

- Campigne ? Lontano ? Euss... smarriti...

- Il cause bien, murmura Cidrolin, mais parle-t-il l'européen vernaculaire ou le néo-babélien?

- Ah, ah, fit l'autre avec les signes manifestes d'une vive satisfaction. Vous ferchtéer l'iouropéen?

- Un poco, répondit Cidrolin; mais posez là votre barda, nobles étrangers, et prenez donc un glass avant de repartir.

- Ah, ah, capito: glass. (18)

Nesse diálogo, algumas palavras são mantidas nas línguas originais, casos em que mantivemos também na tradução; ou-

TRADTERm, 16, 2010, p. 231-255 
tras tiveram a pronúncia representada segundo a grafia francesa, casos em que procuramos, na tradução, representar com a grafia do português:

- Exquiuzi-ãs, disse o campista macho, ma wie sind lost.

- Bom começo, replica Cidrolin.

- Capito? Egarrirtes... lostes.

- Triste sorte.

- Câmpingue? Lontano? Eh... smarriti...

- Ele fala bem, murmurou Cidrolin, mas será que fala o europeu vernacular ou o neo-babélico?

- Ah, ah, fez o outro com sinais manifestos de uma viva satisfação. Você falar iuropeu?

- Un poco, respondeu Cidrolin; mas tirem suas tralhas, nobres estrangeiros, e tomem um glass antes de partir.

- Ah, ah, capito: glass.

\subsection{Provérbios}

Num episódio em que o povo toma conhecimento do boato de que o cavalo do duque fala, começam a comentar o caso citando vários provérbios. No entanto, não se trata de provérbios existentes, mas inventados por Queneau:

- Animal qu'a parlé, âme damnée.

- Si le coq a ri tôt, l'haricot pue trop.

- Quand l'huître a causé, l'huis est très cassé.

- À poisson qui cause, petit cochon peu rose.

- Si bêle le zèbre ut, voilà Belzébuth.

Et autres prouverbes de vaste salaison issus du fin fond aussi faux que lorique de la sapience îledefrançouèse. (3435)

Nesse caso, o que importa não é o sentido dos provérbios; basta que se refiram a animais, já que o motivo é o cavalo que fala. O importante é manter as rimas e a forma de provérbios. Na última frase há ainda um trocadilho "faux que lorique", (folclorique). Para mantê-lo, acrescentamos o adjetivo "amorfo", obtendo "falso, amorfo ou clórico" (folclórico): 
- Animal falou, alma se danou

- Galo que canta cedo, feijão que fica azedo.

- Se a ostra cisma, é o ostracismo.

- Pra peixe que prosa, leitãozinho rosa.

- Se bale a zebra uh, é Balzebu.

$\mathrm{E}$ outros provérbios de grande alcance tirados do fundo

falso, amorfo ou clórico da proverbial sapiência francesa.

\subsection{Marcas de lingua falada}

Como marcas de língua falada, encontramos repetições, mudanças ortográficas para reresentar a fala e imitação da fala (sotaque, gagueira, sobreposição de turnos conversacionais). É o que exploramos nesta seção.

\subsubsection{Repetições}

Queneau dizia que no romance, como no poema, há rimas e assonâncias. Essas rimas manifestam-se por motivos, cenas, frases ou simplesmente palavras, que devem ser repetidos e aparecerem segundo um ritmo pré-definido. No capitulo IV, temos um exemplo de frase que se repete com variações:

Hagarde, Lamélie le regarde.

Il tire des francs de sa poche et tape avec sur la table. Il dit d'une voix assez haute :

- Garçon.

Lamélie, hagarde, le regarde.

(...)

Il assèche son demi et se lève prestement.

Lamélie le regarde, hagarde. (48-49)

Além da repetição da frase, temos também uma rima interna que procuramos manter na tradução, ainda que para isso tivéssemos de substituir o verbo "regarde" por uma locução: "dá uma mirada":

Desvairada, Aamélia dá-lhe uma mirada.

Ele puxa uns francos do bolso e bate com eles na mesa.

TRADTERm, 16, 2010, p. 231-255 
Diz em voz bem alta:

- Garçom.

Aamélia, desvairada, dá-lhe uma mirada.

(...)

Ele seca seu chope e levanta-se com presteza.

Aamélia dá-lhe uma mirada, desvairada.

\subsubsection{Mudanças Ortográficas}

Com relação a mudanças ortográficas, encontramos palavras estrangeiras, como "camping" com grafia que reproduz a pronúncia francesa: "- Pardon, monsieur, dit-elle. Le camp de campigne pour les campeurs, s'il vous plaît ?” (37); caso em que traduzimos com uma grafia que também não é usual em português, mas que reproduz a pronúncia: “- Desculpe, senhor, disse ela. O campo de câmpingue para campistas, por favor?” .

Há também mudanças ortográficas de palavras francesas, sempre imitando a pronúncia popular:

- Ttt, ttt. Je n'en ai pas encore fini avec les animaux qui parlent. Et les houatures ? Viennent-elles de Dieu ou du Diable?

- Les houatures ? Point ne sais ce que c'est. (45)

Procuramos, nesse caso, encontrar uma palavra em português, cuja pronúncia também pudesse ser representada de modo análogo:

- Ttt, ttt. Ainda não acabei com os animais que falam. E os zotomóvis? Vêm de Deus ou do Diabo?

- Os zotomóvis? Não tenho idéia do que seja.

Outras vezes, Queneau utiliza o que ele chamava de "ortograf fonétik", a transcrição de uma frase inteira como se fosse uma só palavra, procedimento que já tinha tornado conhecido em seu romance anterior Zazie dans le métro. Vejamos dois exemplos: no lugar de "ce que c'est”, encontramos “... regarder dans les livres pour savoir cexé." (63) e, ainda, no lugar de "Stèphe s'est tu Stène aussi", encontramos "Stèfstu esténoci" (202). No 
primeiro caso, mantivemos, em português, algo semelhante: "olhar nos livros pra saber uquiéquié." No segundo caso, no entanto, na impossibilidade de traduzir da mesma forma, procuramos compensar com marcas de oralidade próprias do português, como a redução do ditongo no final do verbo "calou" e a redução de "mb" a "m" em também: "Estêvão sicalô Stenes tamém.".

\subsubsection{Imitação da fala - sotaque}

Exemplo de imitação de sotaque encontramos na resposta do taberneiro à questão do duque de Auge sobre o que há para comer: "Du bortch qui est de la choupe aux chous echclavons et des tripes à la viducasse, le tout arrosé de vin des coteaux de Suresnes." (31-32). Nesse caso, trata-se de imitação de sotaque da região de Auvergne. Como o leitor brasileiro provavelmente não conhece esse sotaque, reproduzi-lo em português não causaria o efeito desejado. Optamos por compensar com a redução do ditongo de "couve", que ocorre na fala brasileira: "Bortsch, que é uma sopa de cove eslava e tripas à viducasse, tudo regado a vinho das costas de Suresnes".

\subsubsection{Imitação da fala - gagueira}

Encontramos imitação de gagueira em duas ocasiões, em ambas para representar o nervosismo ou o medo das personagens. A primeira, na fala do alquimista Timoleo Timolei, quando percebe que o cavalo pode falar. "Oooh, dit l'alchimiste devenu soudain pâle et bègue, un cheche, un vaval... un cheval... qui qui... caucause... " (139), reproduzida em português: "- Oooh, disse o alquimista que de repente ficou pálido e gago, um caca, um vava... um cavalo... queque... fafala...". A outra, quando, em 1789, Stènes fala a Pouscailou sobre a revolução que se aproxima: "Quequelle revovolutiontion ?" (169), também reproduzida em português: "Queque revovolulução?".

TradTerm, 16, 2010, p. 231-255 


\subsubsection{Imitação da fala - turnos conversacionais}

Outra manifestação de imitação da fala, a sobreposição de turnos conversacionais, ocorre em duas ocasiões. Abaixo reproduzimos a primeira, no capítulo II, quando Cidrolin conversa com um passante:

- Vous êtes de ces nomades...? demanda Cidrolin poliment.

- Moi? Point. J'habite l'hôtel...

- et moi cette péniche...

- un hôtel de luxe même...

- immobile...

- il y a des vatères dans la salle de bains...

- amarrée...

- l'ascenseur...

- je pourrais même avoir le téléphone...

- le téléphone dans les chambres...

- il y a un numéro bleu avec des chiffres comme pour une maison...

- avec l'automatique pour l'étranger...

- c'est le vingt et un...

- et au rez-de-chaussée, il y a un bar...

- de ma chambre, je pourrais pêcher...

- américain...

- je pourrais pêcher, sije pêchais, mais je n'aime pas pêcher.

- Vous avez bien raison, dit le passant s'intéressant brusquement aux propos de son interlocuteur; la pêche c'est aussi cruel que les courses de taureaux... (30)

Nesse caso, um verdadeiro diálogo de surdos, foi mantido em nossa versão com uma tradução literal, provocando no leitor o mesmo estranhamento:

- O senhor é um desses nômades...? perguntou Cidrolin educadamente.

- Eu? De jeito nenhum. Moro no hotel...

- e eu nessa chata...

- um hotel de luxo mesmo...

- imóvel...

- tem latrina no banheiro...

- amarrada... 


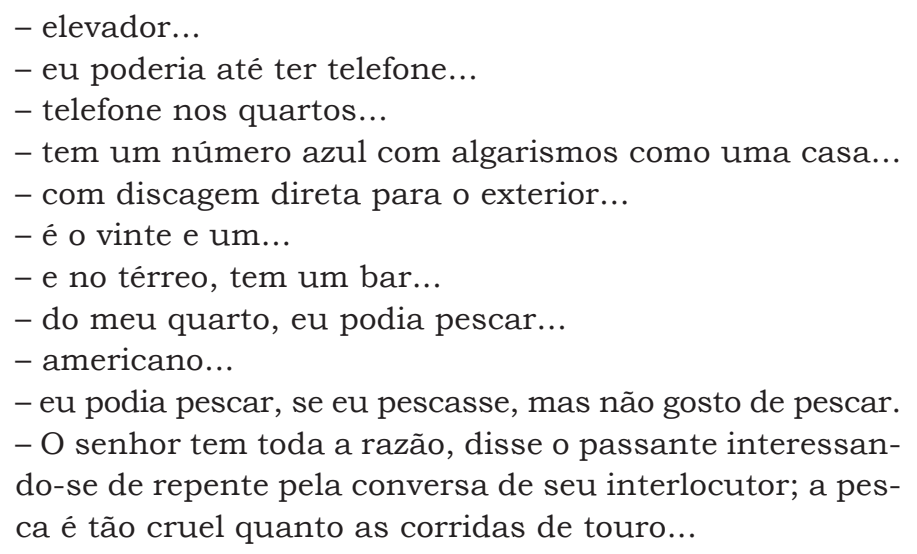

\subsection{Desvios sintáticos}

Os desvios sintáticos são talvez a marca de oralidade que mais implicações tem para a tradução, uma vez que são característicos do francês e por isso não podem ser reproduzidos em português numa tradução literal. Nesses casos, procuramos restituir as ocorrências através de outros desvios sintáticos próprios do português.

\subsubsection{Supressão do sujeito}

Como em francês o sujeito gramatical está sempre presente na frase, a supressão desse elemento caracteriza um desvio próprio da língua falada. Vejamos dois exemplos. No capítulo IV, encontramos "-Faut que je me tire."(48), onde é omitido o sujeito "il", e no capítulo VI, "-M'en fous. M'en irai trouver le roi quand même." (74), onde o sujeito "je" é omitido nas duas frases. Ora, como em português o sujeito pode ser omitido e não constitui desvio, procuramos manter o efeito de oralidade com outros recursos. No primeiro caso, a supressão do "r" final do infinitivo e, ao mesmo tempo, a utilização de uma expressão popular: "Tenho que puxá o carro.". No segundo exemplo, o efeito de oralidade foi restituído pela redução dos verbos "estou" e "vou", além da já citada supressão do "r" do infinitivo: "- Tô me lixando. Vô encontrá o rei assim mesmo.".

TradTerm, 16, 2010, p. 231-255 


\subsubsection{Supressão do "ne" da negação}

Trata-se de outro traço de oralidade do francês que não tem correspondente em português. No capítulo $\mathrm{V}$, encontramos dois exemplos: "- Surtout, vous allez pas faire la course, dit Sigismonde" (61) ; três páginas adiante, temos: "... tu les vois pas en même temps que la chose se passe." (64). Procuramos reproduzir, na tradução, marcas de oralidade correntes em português: redução de "você(s)" para "cê(s)", alteração na pronúncia do advérbio "não" e supressão do "r" do infinitivo. Assim, a tradução das duas frases ficou da seguinte forma: "- Cês num vão apostá corrida, né? diz Sigismunda." e "...cê num vê elas ao mesmo tempo em que a coisa acontece.".

\subsubsection{Uso do apóstrofo em "tu" e "qui"}

Essas marcas de oralidade também não têm correspondente em português e, portanto, tiveram de ser substituídas por outras. No capitulo IV, encontramos "-T'es pas sûre de monter. Va y avoir du monde." (49), em vez de "- Tu n'es pas sûre de monter. Il va y avoir du monde.". No capitulo seguinte, "Un jour, y a eu des gens qu'ont signé un armistice...(64), em vez de "Un jour, il y a eu des gens qui ont signé un armistice...". Nessas frases, além da supressão do sujeito e do "ne" da negação, vistas nos itens anteriores, há a elisão indevida do "tu" e do "qui". Para manter, em português, a impressão de língua falada, no primeiro exemplo usamos mais uma vez a redução de "você" e a supressão do "r" dos infinitivos. No segundo exemplo, optamos pela falta de concordância de número, ocorrência comum no português falado no Brasil. A tradução ficou, respectivamente: "-Cê nem sabe se vai consegui subi. Vai tê muita gente." e "Um dia umas pessoa assinaram um armistício...".

\subsubsection{Conjugação verbal}

Esta não é propriamente uma marca de oralidade normal do francês, mas é utilizada nas falas das canadenses que procuram o camping, em que o verbo é conjugado na primeira pessoa 
do plural em vez da primeira do singular. Dessa forma, encontramos no capítulo III:

- Je vous étonnons ? sussurra-t-elle.

- Nullement, répondit Cidrolin.

- Je sommes iroquoise, dit-elle, et je m'en flattons.

- Il y a de quoi.

- C'est de l'ironie?

- Non, non. Ne mettez pas d'ire au quoi.

- Je vous avons réveillé ?

- Je mentirais en disant que non.

- Alors vous m'en voulez ?

- Ma mie, ne marivaudez point.

- Et ce campigne ? Vous allez finir par me dire où il perche? Cidrolin fit des gestes qui déterminèrent la situation du lieu à dix centimètres près.

- Je vous remercions, dit l'Iroquoise canadienne, et je vous prions de m'excuser d'avoir troublé votre sieste, mais on m'avait dit que les Français étaient si obligeants..., si serviables... (38, grifo nosso)

Em português não ocorre essa mistura entre as pessoas do singular e do plural na conjugação. Como o trecho refere-se à fala de uma canadense que Cidrolin acabara de identificar como uma pele-vermelha, decidimos manter os verbos no infinitivo, reproduzindo um tipo de fala que, graças aos filmes americanos, tornou-se o estereótipo da fala dos pele-vermelhas:

- Eu o espantar? sussurrou ela.

- De jeito nenhum, respondeu Cidrolin.

- Eu ser iroquesa, disse ela, e me orgulhar muito disso.

- Tem de quê.

- Isso é ironia?

- Ir o quê? Não, não é isso.

- Eu o acordar?

- Eu estaria mentindo se dissesse que não.

- Então está com raiva de mim?

- Minh'amiga, não faça drama.

- E esse câmpingue? Não vai me dizer onde é que fica?

Cidrolin fez gestos que determinaram a localização do lugar com uma aproximação de cerca de dez centímetros.

TRadTerm, 16, 2010, p. 231-255 
- Eu agradecer, disse a iroquesa canadense, e pedir que me desculpe por ter perturbado sua sesta, mas dizem que os franceses são tão prestativos... tão prestimosos... (grifo nosso)

\section{Considerações Finais}

Ao realizarmos uma tradução literária, estamos diante de um texto que, segundo Reiss, foi escrito para transmitir conteúdos artísticos, o que determina uma tradução em que o tradutor deve identificar-se com a intenção artística do autor e procurar manter a qualidade artística do texto.

Se, ao determinar o objetivo de sua tradução, segundo a teoria do escopo de Vermeer, o tradutor concluir que o texto de chegada deve produzir no seu leitor as impressões que o texto de partida produz no leitor da língua fonte, estamos diante de uma tradução que se propõe a ser equivalente ao original.

No entanto, se em qualquer tradução é impossivel a identidade absoluta, na tradução literária, como diz Mário Laranjeira, não devemos buscar tampouco a equivalência de sentido, ou seja, a transmissão da mesma mensagem, já que o texto não tem um sentido intrínseco; devemos, em vez disso, produzir um texto que seja o mais homólogo possivel do original. "Assim, não é raro que a fidelidade à significância do texto, que deve sempre prevalecer, imponha, na tradução do poema, infidelidades no nível estritamente semântico" (Laranjeira, 2003:126). Embora esse princípio refira-se à tradução de poemas, aplica-se também à prosa literária, notadamente no caso de Raymond Queneau que, na composição, trata a forma e o uso da língua de maneira muito próxima aos da poesia.

Como pudemos observar nos exemplos analisados neste artigo, mesmo em se tratando de prosa, a ideia frequente de que a fidelidade semântica, ou seja, a transmissão da mensagem, do sentido, é a mais importante nem sempre se aplica quando se trata de literatura, pois muitas vezes o significante é mais importante do que o significado. O tradutor é obrigado a fazer escolhas, como se estivesse traduzindo poemas, de forma que o texto na língua de chegada possa ser o mais homólogo possivel 
ao da lingua de partida e, sempre que possivel, provocar no leitor da lingua/cultura de chegada as mesmas impressões provocadas no leitor do original.

No caso de Les Fleurs bleues, um dos elementos importantes na construção da significância são as expressões de oralidade, encontradas tanto nas falas de personagens quanto na própria narração. Nos romances do século XX, essas expressões podem surgir em formas que, de alguma maneira, contrariam a norma culta da língua, antes seguida à risca pelos escritores.

É necessário, pois, ao efetuar-se a tradução de uma obra desse gênero, estar atento à presença das marcas de oralidade e evitar que elas sejam apagadas na língua de chegada por uma "correção" na sintaxe ou na ortografia, como se os desvios não existissem no original. Ao contrário, deve-se buscar na língua de chegada marcas e desvios que possam manter a presença da oralidade no texto traduzido. Num romance como Les Fleurs bleues, em que a ocorrência da oralidade é resultado de uma busca consciente do autor e que é uma das razões do interesse da obra, seu apagamento implicaria a destruição de traços que são a estrutura mesma da narrativa.

\section{Referências bibliográficas}

AZENHA JR, J. (1999) Tradução Técnica e Condicionantes Culturais Primeiros passos para um estudo integrado. São Paulo: Humanitas. BOURJEA, M. (1996) Traduzir Clarice Lispector assim como ela escreve. In: COSTA, L. A. (Org.). Limites da Traduzibilidade. Salvador: EDUFBA, pp. 121-133.

ESPINASSE, M. (1999) Étude sur Les Fleurs bleues. Paris: Ellipses. LARANJEIRA, M. (2003) Poética da Tradução. São Paulo: EDUSP. OULIPO (1973) La littérature potentielle. Paris: Gallimard, 1973. POUILLOUX, J. (1991) Les fleurs bleues de Raymond Queneau. Paris: Gallimard.

QUENEAU, R. (1965) Les fleurs bleues. Paris: Gallimard.

REISS, K. (2004) Type, kind and individuality of text - Decision making in translation. In: VENUTI, L. The Translation Studies Reader. New York: Routledge, pp. 160-171.

TRADTERm, 16, 2010, p. 231-255 
URBANO, H. (2000) Oralidade na Literatura - O caso Ruben Fonseca. São Paulo: Cortez.

VERMEER, J. Skopos and Commission in Translational Action (2004) In: VENUTI, L. The Translation Studies Reader. New York: Routledge, pp. 222-232. 